\title{
NILAI KESENIAN BUDAYA TARIAN CACI PADA MASYARAKAT MANGGARAI KABUPATEN MANGGARAI TIMUR
}

\author{
Hironimus Jampi ${ }^{1}$, Muhammad Nawir ${ }^{2}$, Hadisaputra ${ }^{3}$ \\ ${ }^{1}$ Pendidikan Sosiologi, Universitas Muhammadiyah Makassar \\ Email: hironimusjampi@gmail.ac.id \\ ${ }^{2}$ Pendidikan Sosiologi, Universitas Muhammadiyah Makassar \\ Email: muhammadnawir@unismuh.ac.id \\ ${ }^{3}$ Pendidikan Sosiologi, Universitas Muhammadiyah Makassar \\ Email: alkemis.institute@gmail.com
}

\begin{abstract}
The main problem in this study is the values of dance culture in the Manggarai community, Kazu Wangi Village, East Manggarai Regency, is that most of the Kazu Wangi village people reflect the culture and daily lives of the Manggarai community. This study aims to describe the cultural values of dancing in the Manggarai community, Kazu Wangi Village, East manggrai Regency, this research method uses ethnographicqualitative research, a method that uses direct research on human activities in socio-culture. Data collection is done by means of observation, interviews, and literature study. To examine the cultural values of the people in Manggarai Village, Kazu Wangi Village is used to request folklore. Analysis of the data in several ways, namely data reduction, data presentation and conclusions, while the validity of the data technique uses source tringulation, time and technique. The results of the study prove that the values of Caci dance culture only exist in Manganggrai and animate all aspects of Manggarai people's lives. The caci dance is always performed after harvest, between July and September, and is performed for three days. Caci dance also contains symbolic meaning, symbolizing virility, heroism, hospitality, grandeur and high sportsmanship spirit. Caci dance also has many functions for people who live in the village of Kazu Wangi, as a means of tourism, as a means of communication with God and the ancestors, as well as educational media.
\end{abstract}

Keywords: Values of Dance Arts and Culture Values.

Abstrak. Masalah utama dalam penelitian ini adalah nilai-nilain kesenian budaya tarian caci pada masyarakat manggarai Desa Kazu wangi Kabupaten Manggarai Timur, bahwa sebagian besar masyarakat Desa Kazu wangi Kabupaten Manggarai Timur sangat antusias dalam melestarikan budaya tarian caci yang merupakan tarian khas masyarakat manggarai pada umumnya, yang merefleksikan kebudayaan dan keseharian masyarakat manggarai. Penelitian ini bertujuan untuk mendeskripsikan nilai-nilai budaya tarian caci pada masyarakat Manggarai Desa Kazu wangi Kabupaten manggrai Timur, metode penelitian ini menggunakan penelitian etnografi- kualitatif, suatu metode yang menggunakan observasi langsung mengenai kegiatan manusia dalam konteks sosial-budaya.

Penggumpulan data dilakukan dengan cara observasi, wawancara, dan studi kepustakaan. Untuk mengkaji nilai-nilai budaya tarian caci pada masyarakat manggarai Desa Kazu Wangi digunakan pendekatan folklor. Teknik analisis data melelui beberapa tahap yaitu reduksi data, penyajian data dan penarikan kesimpulan, sedangkan teknik keabsahan data menggunakan tringulasi sumber, waktu dan teknik. Hasil penelitian memperlihatkan bahwa nilai-nilai kesenian budaya tarian caci hanya ada dalam kebudayaan manggrai dan menjiwai semua aspek kehidupan orang manggarai. Tarian caci selalu dipentaskan pasca panen, antara bulan juli sampai dengan september, dan dilakuan selama tiga hari. Tarian tarian caci juga mengandung makna simbolis, 
melambangkan kejantanan, kepahlawanan , keramaiaan ,kemegahan dan semangat sportivitas yang tinggi. Tarian caci juga memiliki banyak fungsi bagi kelangsungan hidup masyarakat Desa kazu wangi, sebagai komoditas pariwisata, sebagai sarana komunikasi dengan Tuhan dan para leluhur, serta media pendidikan.

Kata Kunci: Nilai-Nilai Kesenian dan Budaya Tarian Caci.

\section{PENDAHULUAN}

Kebudayaan yang sudah melekat dalam masyarakat dan sudah turun temurun sejak dahulu, akan semakin terkonsep dalam kehidupan masyarakat sehingga menjadi sebuah kepercayaan terhadap hal-hal yang berhubungan dengan sebuah keyakinan yang sulit untuk dihilangkan. Kepercayaan-kepercayaan yang masih berkembang dalam kehidupan suatu masyarakat, biasanya dipertahankan melalui sifat-sifat lokal yang dimilikinya.

Tarian Caci merupakan kesenian asli Manggarai yang penuh dengan keunikan-keunikan mulai dari jenis tarian, kostum tari, property yang digunakan oleh penari, sampai pada bentuk komposisi musik iringannya. Karena keaslian dan keunikannya tersebut Pemerintah dan beberapa Organisasiorganisasi dari Manggari yang menyebar di seluruh Indonesia mencoba untuk melestarikan tarian Caci sebagai salah satu ciri khas kesenian yang berasal dari Kabupaten Manggarai.

Caci adalah salah satu budaya Manggarai yang merupakan ekspresi tradisional budaya Manggarai. Di Manggarai Flores NTT, Tarian Caci merupakan suatu permainan adu ketangkasan antara dua orang laki-laki dalam mencambuk dan menangkis cambukan lawan secara bergantian. Tarian Caci terlihat begitu heroik dan indah karena merupakan kombinasi antara Lomes (keindahan gerak tubuh dan busana yang dipakai), Bokak (keindahan seni vokal saat bernyanyi), dan Lime (ketangkasan dalam mencambuk atau menangkis cambukan lawan). Caci secara etimologis berasal dari dua kata yaitu $\mathrm{Ca}$ yang berarti satu, dan $\mathrm{Ci}$ yang berarti lawan. Jadi Caci berarti tarian seorang melawan seorang yang lain.

Tarian ini menggambarkan suka cita masyarakat Manggarai. Caci merupakan tarian kesatriaan para pria.Tarian Caci adalah sebuah tari perang di mana sepasang lelaki bertarung di sebuah lapangan dengan menggunakan cambuk dan perisai. Penari yang memegang cambuk bertindak sebagai penyerang dan penari lainnya yang memegang perisai bertindak sebagai seorang yang bertahan. Para pemain Caci dibagi menjadi dua kelompok yang secara bergantian bertukar posisi sebagai kelompok penyerang dan sebagai kelompok bertahan. Caci selalu dimainkan oleh kelompok tuan rumah (ata one) dan kelompok pendatang dari desa lain (ata peang). Beberapa pernak-pernik dalam Caci dalam bahasa Manggarai adalah, panggal, lalong ndeki, nggororng, nggiling, aging, larik, sapu dan songke.

Dalam Caci, tidak boleh menyerang bagian tubuh dari pinggang ke bawah. Para pemain hanya diperbolehkan menyerang bagian tubuh dari pinggang ke atas. Bila pukulan lawan tidak dapat ditangkis, maka pemain akan terkena pecutan dan mendapatkan luka cambukan. Dan jika mata terkena cambukan maka pemain dinyatakan kalah (beke), dan kedua pemain langsung segera diganti. Tari Caci hanya dilaksanakan apabila ada acara penting. Misalnya pada upacara penti, ritual tahun baru, upacara pembukaan lahan, dan upacara besar lainnya.Dilihat secara sepintas, Caci adalah sebuah tontonan hiburan yang mengandung unsur kekerasan di dalamnya. Namun jika kita melihat lebih dalam, kita akan menyadari bahwa tarian ini merupakan budayatradisional Manggarai yangmerupakan ekspresi budaya Manggarai.

Menurut Edi, Maria Grace Putri, program studi pendidikan pancasila dan kewarganegaraan, jurusan hukum dan kewarganegaraan, fakultas ilmu sosial, Universitas Negeri Malang, dengan judul "Nilai Moral yang Terkandung dalam Tarian Caci di Desa Batu Cermin Kecamatan Komodo Kabupaten Manggarai Barat, dalam peneliti Edi, Maria Grace Putri, Nilai moral merupakan nilai mengacu pada tindakan manusia berkaitan dengan baik atau buruknya tindakan manusia dalam 
kehidupannya. Nilai moral berkaitan dengan perbuatan baik dan buruk yang menjadi dasar kehidupan manusia dan masyarakat. Nilai-nilai moral yang ada dalam suatu kesenian dapat menjadi nilai-nilai yang bisa ditiru dan dipraktekkan dalam kehidupan kita. Berkaitan dengan hal tersebut maka penelitian ini bertujuan untuk mendeskrpsikan nilai-nilai moral yang terkandung dalam tarian caci agar nilai-nilai moral tersebut bermanfaat baik di depan kita.

Teori Materialisme kebudayaan adalah salah satu paham yang beranggapan bahwa manusia hidup didunia, dia sebenarnya hidup didunia materi. Dia mau hidup, harus makan, dia mau menata sistem nilai dan budayaanya harus menggunakan alat (materi). Materialisme berpandangan kebudayaan adalah hasil kumpulan pikiran yang dipelajari dan kelakuan yang diperlihatkan oleh anggota dari kelompok sosial masyarakat, yang diwariskan dari satu generasi ke generasi berikutnya. Pandangan materialisme ini berkaitan dengan hubungan manusia dengan lingkungannya, oleh Marvin Haris, disebut variabel yang bersifat empiris dan ini distilahkan dengan teknoekonomi dan teknolingkungan.

Berdasarkan teori tentang kebudayaan yang sudah dipaparkan diatas, peneliti menyimpulkan bahwa kebudayaan adalah seluru cara dari kehidupan masyarakat dan tidak hanya mengenai sebagian tatacara hidup saja yang dianggap lebih tinggi dan lebih diinginkan" jadi, kebudayaan menunjuk pada berbagai aspek kehidupan. Istilah ini meliputi cara-cara berlaku, kepercayaankepercayaan dan siskp-sikap dan juga hsil dari kegiatan manusia yang khas untuk suatu masyarakat atau kelompok penduduk tertentu.

Hal ini terjadi karena manusia mencontohi sesuatu yang dilakukan oleh generasi sebelumya atau lingkungan disekitarnya yang dianggap baik dan berguna dalam hidupnya begitu juga dengan budaya tarian caci yang dimiliki oleh masyarakat manggarai yang merupakan hasil dari realitas obyektivitas manusia menghasilkan kenyataan obyektif hasil ciptaan leluhur terdahulu yang diserap kembali oleh generasi setelahnya atau selalu meregenerasikan nilai-nilai budaya tarian caci yang merupakan warisan leluhur. Penelitian terdahulu di atas membahas tentang identitas budaya dan maknanya dalam tarian caci orang manggarai dan nilai moral yang terkandung dalam tarian caci, maka dari itu dalam penelitian ini, peneliti membahas tentang Nilai-nilai budaya dalam tarian caci pada masyarakat manggarai desa kazu wangi kabupaten manggarai timur.

\section{METODE PENELITIAN}

Jenis penelitian yang digunakan dalam penelitian ini adalah jenis metode penelitian menggunakan penelitian etnografi-kualitatif dalam pendekatan fenomenologi di mana data diperoleh melalui pengamatan langsung dengan cara observasi, wawancara, dan studi pustaka (Bogdan dan Taylor dalam Sumaryanto, 2010: 74). Dalam penelitian etnografi kualitatif, data yang diperoleh tidak dapat dituangkan dalam bentuk bilangan atau angka statistik, peneliti memaparkan gambaran mengenai hasil yang diteliti dalam bentuk naratif untuk mendeskripsikan atau menggambarkan fenomena-fenomena yang ada di objek penelitian. Dalam hal ini, yang menjadi objek penelitian adalah Nilai- Nilai Kesenian Budaya Tarian Caci Pada Masyarakat Manggarai Desa Kazu Wangi Kabupaten Manggarai Timur

Peneliti memfokuskan penelitian ini pada konsep/ pandangan, ciri/ karakteristik Kesenian budaya Tarian Caci merupakan sebuah rumusan masalah penelitian ini. Penggunaan metode penelitian etnografi kualitatif merupakan cara untuk membedah materi penelitian yang mengacu kepada tujuan penelitian yang telah dipaparkan.

\section{HASIL DAN PEMBAHASAN}

Identitas budaya tercermin dalam bahasa, nyanyian, cara berpakaian, dan etika moral. Identitas ini termanifestasi dalam tarian caci di manggarai. Berdasarkan hal ini, kita akan melihat makna yang terkandung dalam budaya tarian caci masyarakat manggarai. 


\section{Nilai Bahasa dan Nyayian ( keindahan, keselaransan, dan kerendahan hati)}

Tarian caci pada dasarnya menarik ketika seorang pemain caci setelah menerima pukulan atau memberi pukulan, berbicara dan bernyanyi. Pembicaraan dan nyanyian yang dilakukan menggunakan bahasa yang indah dengan istilah-istilah yang menarik perhatian penonton.Bahasa yang digunakan tentunya menggunakan bahasa daerah manggarai.Keunggulan seorang pemain caci dilihat dari keindahan dalam berkata-kata dan menyanyi selaras dengan caranya bertarung yang diiringi dengan bunyi gong dan gendang serta nyanyian lainnya (sanda). Selain itu, bahasa dan nyanyiannya akan indah ketika tidak membuat orang yang menonton dan khususnya lawannya tersinggung. Ataupun sebaliknya, ketika peterung tersebut terkena pukulan, keindahan bahasa dalam menyampaikan apa yang menimpanya secara menarik dengan istilah-istilah tersembunyi dan bermakna.

Berdasarkan hasil wawancara dengan pemain caci yaitu bapak yang berinisial $F \mathrm{M}$, (34 tahun) berpendapat bahwa :

"Dalam memerankan permainan caci kita harus memiliki kecakapan dalam berbahasa dan memiliki keindahan suara karena itu merupakan sebuah modal yang dapat menarik animo para penonton sehingga dengan demikian potensi yang kita miliki dapat di akui oleh orang banyak tegasnya".

Dari hasil wawancara dengan bapak inisial FM, dapat disimpulkan bahwa pada dasarnya seorang pemain caci harus memiliki kecakapan dalam berbahasa dan memiliki suara yang indah dalam menggunakan bahasa daerah manggarai yang dapat dilihat dari keindahan dalam berkatakata dan menyanyi selaras dengan caranya bertarung yang diiringi dengan bunyi gong dan gendang.

Tarian caci pada dasarnya menarik ketika seorang pemain caci setelah menerima pukulan atau memberi pukulan, berbicara dan bernyanyi. Pembicaraan dan nyanyian yang dilakukan menggunakan bahasa yang indah dengan istilah-istilah yang menarik perhatian penonton. Bahasa yang digunakan tentunya menggunakan bahasa daerah manggarai.

\section{Nilai Cara berpakaian.}

Dalam memerankan tarian caci ada pakaian tertentu yang di gunakan oleh para penari sehingga tercipta keserasian dan kekompakan dalam pertunjukan tarian caci. Pakaian yang digunakan antara lain panggal yang berfungsi sebagai penyokon kepala, selendang, kain songke, ikat pinggan, nggiring, dan celana panjang berwarna putih.

Demikian juga saat wawancara dengan bapak yang berinisial GJ, (25 tahun ) sebagai penari berpendapat bahwa:

"sebagai seorang yang memiliki bakat bermain caci tentunya kita harus mempersiapkan perlengkapan-perlengkapan yang menunjang terlaksananya pertunjukan tarian caci baik dari perlengkapan yang terkecil hingga yang terbesar sehingga dapat menciptakan nilai keserasian saat mementaskan tarian caci".

Dari hasil wawancara dengan bapak inisial GJ, dapat disimpulkan bahwa sebagai seorang pemain caci yang memiliki bakat, tentu haruslah memiliki berbagai perlengkapan-perlengkapan pakaian yang dapat menunjang terlaksananya pertunjukan tarian caci, sehingga tercipta keserasian dan kekompakan dalam memerankan tarian caci.

Peralatan tarian caci yang terbuat dari kulit kerbau melambangkan kekuatan, ketenangan, kerendahan hati, dan tidak emosional, sedangkan bentuknya yang relatif bundar melambangkan adanya satu titik pusat yang mengatur semuanya, itulah Tuhan Yang Maha Esa. 


\section{Nilai Etika Moral}

Permainan caci atau tarian caci merupakan sebuah identitas budaya orang manggarai. Meskipun, ini adalah sebuah pertarungan, tetapi etika moral tetap menjadi hal yang utama yang harus diperhatikan. Etika moral kemanusiaan adalah yang utama dalam tarian ini. Dalam hal ini, pertarungan atau perkelahian tentunya akan berlawanan dengan etika moral, tetapi dalam permainan caci, etika moral tetap menjadi yang utama lewat sikap tanggun jawab dan saling menghargai dalam sebuah pertarungan.

Berdasarkan hasil wawancara dengan bapak yang berinisial GE, ( 30 tahun ) sebagai anggota masyarakat mengatakan bahwa:

"saya sudah sering mengikuti pertunjukan tarian caci dibeberapa kampung namun sebelum saya dan teman-teman ikut serta dalam mementaskan tarian caci ada etika moral yang harus dipatuhi bersama demi terlaksananya pementasan tarian caci sesuai dengan apa yang diharapkan oleh tokoh masyarakat setempat, dengan kami sebagai pengunjung untuk memeriahkan pelaksaan tarian caci sehingga terhindar dari hal-hal yang tidak di inginkan bersama".

Dari hasil wawancara dengan bapak inisial GE (30 tahun) dapat disimpulkan bahwa hal yang sadari bersama adalah pentingnya mengerti dan memahami etika moral yang terkandung dalam budaya tarian caci sehingga terciptanya sebuah situasi yang kondusif baik tokoh masyarakat setempat yang berfungsi sebagai pelayan terlaksananya budaya tarian caci dan juga bagi para pengunjung yang memeriahkan atau menyukseskan pementasan atau pertunjukan budaya tarian caci .

Pemain caci atau tarian caci merupakan sebuah identitas budaya orang manggarai. Meskipun, ini adalah sebuah pertarungan, tetapi etika moral tetap menjadi hal yang terutama yang harus diperhatikan. Etika moral kemanusiaan adalah yang terutama dalam tarian ini. Dalam hal ini, pertarungan atau perkelahian tentunya akan berlawanan dengan etika moral, tetapi dalam permainan caci, etika moral tetap menjadi yang utama lewat sikap tanggun jawab dan saling menghargai dalam sebuah pertarungan.

\section{Nilai Darah, Keringat, dan Air Mata (kejantanan, keramaian, kemegahan, dan sportivitas)}

Darah, keringat, dan air mata terus menerus hadir selama tarian caci berlangsung. Darah, keringat, dan air mata ini tidak akan membuat orang-orang yang hadir dan bertarung mengalah. Mereka tidak pernah menyerah sampai di katakan "Rowa" (mati). Tetapi, mati di sini berarti petarung terkena cambukan di daerah kepala (wajah) dan tangan. Meskipun tubuh mereka terkena cambukan hingga berdarah, berkeringat dan air mata mengalir malah jusrtu akan menciptakan pertarungan semakin seru.

Sebab darah, keringat dan air mata dalam tarian caci mengandung makna kepahlawanan dan keperkasaan. Namun dalam caci, keperkasaan tidak harus dilakoni lewat kekerasan namun juga lewat kelembutan yang ditunjukkan dalam gerakan-gerakan yang bernuansa seni. Tarian caci diiringi bunyi gendang dan gong serta nyanyian para pendukungnya yang menunjukkan kemegahan acara tersebut, namun suatu hal yang sangat penting dari sebuah pementasan tarian caci adalah bagaimana memberikan makna simbolik bagi masyarakat manggarai yang diantaranya adalah sebagai berikut :

Nilai kepahlawanan yaitu seorang pemain caci harus memiliki jiwa yang menonjol karena keberanian dan pengorbanannya dalam permainan caci, yang tidak harus diakhiri dengan rasa dendam terhadap pemain lawannya.

Nilai keperkasaan yaitu dalam permainan tarian caci, keperkasaan tidak harus dilakoni lewat kekerasan namun juga lewat kelembutan yang ditunjukkan dalam gerakan-gerakan yang bernuansa seni. Nilai sportivitas yaitu dalam permainan tarian caci seorang penari haru bersikap adil (jujur) terhadap lawan, sikap bersedia mengakui keunggulan (kekuatan dan kebenaran ) lawan. 
Berdasarkan hasil wawancara dengan bapak yang berinisial SW, (36 tahun) sebagai seorang penari yang sangat berbakat dalam bidang tarian caci mengatakan bahwa:

"sesuai dengan pengalaman peribadi yang saya perna alami dalam berbagai pertempuran tarian caci, hal yang paling penting untuk kita sadari adalah bahwa pementasan tarian caci itu bukanlah sebuanh pertarungan yang mematikan, walaupun terkandung unsur kekersan didalamnya, tapi tujuan dari pelaksanaan tariaan caci ini adalah sebagai bentuk ekspresi kebahagiaan masyarakat setempat atas berbagai usaha yg dilakukan oleh mereka dalam setahun penuh,jadi ketika setiap penari memamahami hal ini maka dalan permainan caci kita dapat menenemukan nilai-nilai simbolik yang terkandung didalamnya seperti nilai kepahlawanan, nilai keperkasaan, nilai ketangkasan dan nilai sportivitas. Tegasnya.

Dari hasil wawancara bersama bapak inisial SW, (36 tahun) dapat disimpulkan bahwa dalam pementasan tarian caci pentingnya membangun kesadaran bersama atas nilai-nilai yang terkandung dalam budaya tarian caci itu sendiri yang dimana diantaranya nilai etika moral, nilai keringat dan darah, nilai cara berpakaian, dan nilai bahasa dan nyanyian yang diekspresikan oleh para penari saat mementaskan tarian caci, dengan memahami hal tersebut diatas maka pelaksanaan budaya tarian caci akan berjalan dengan baik seperti yang diharapkan oleh tokoh adat dan masyarakat setempat dan juga para pengunjung yang ikut terlibat dalam meramaikan pementasan tarian caci.

Darah, keringat dan air mata dalam tarian caci mengandung makna kepahlawanan dan keperkasaan. Namun dalam caci, keperkasaan tidak harus dilakoni lewat kekerasan namun juga lewat kelembutan yang ditunjukkan dalam gerakan-gerakan yang bernuansa seni. Tarian caci diiringi bunyi gendang dan gong serta nyanyian para pendukungnya yang menunjukkan kemegahan acara tersebut.

\section{KESIMPULAN}

Dari seluruh lingkaran penyusunan dan penelitian yang dibuat oleh penulis, maka penulis menarik sebuah kesimpulan dari keseluruhan tulisan ini. Kesimpulan ini menjadi uraian terakhir dari penulis. Semoga rangkaian tulisan ini mengantar penulis dan pembaca untuk mengetahui apa dan bagaimana itu nilai-nilai budaya tarian caci pada masyarakat manggarai Desa Kazu Wangi Kabupaten Manggarai Timur. Caci merupakan ungkapan syukur yang dimanifestasikan dalam permainan. Caci menjadi sebuah simbol dengan berbagai macam nilai didalamnya, dan nilai nilai itulah yang dikemas dalam keseluruhan permainan caci. Adapun maksudnya ialah agar masyarakat manggarai memiliki nilai juang, mempunyai jiwa sebagai ata rona ( seorang lelaki) pemberani dan gagah perkasa.

Tarian caci memperlihatkan nilai seni yang sangat tinggi, mulai dari gerak seni tarian (lomes), seni suara (bokak), seni lukis ( ornament-ornamen caci), seni rupa atau seni tenun (motif-motif tenunan pada kain songke, selendang, sapu tangan) yangb digunakan penari caci. Kesenian ini memiliki pesan damai didalamnya, seperti semangat sportivitas, saling menghormati, dan diselesaikan tanpa dendam diantara para penari.

\section{DAFTAR PUSTAKA}

Bakker, JWM, 1992, Filsafat Kebudayaan, Sebuah Pengantar, Yogyakarta: kanisius.

Creswell John W. 2009. "Research Design: Pendekatan Kualitatif, Kuantitatif, dan Mixed" Yogyakarta: Pustaka pelajar

Dagur, Anthony Bagul, 1977, Kebudayaan Manggarai Sebagai salah satu Khasanah Kebudayaan Nasional, Surabaya, Ubhara Press.

De Rosari, Anton BL, 1988, Kedudukan Kebudayaan Daerah dalam Pembangunan Kebudayaan Nasional, Kupang.

Depertemen Kebudayaan dan Pendidikan, 2005, Kamus Besar Bahasa Indonesia, Jakarta: Balai Pustaka

Hadi, Y. Sumandiyo. 2005. Sosiologi Tari: Sebuah Pengenalan Awal. Yogyakarta: Pustaka Pelajar. 
Prastowo, 2014. Metode penelitian Kualitatif dalam perspektif Rancangan penelitian Puersen, C.A. Van., 1993, Strategi Kebudayaan, Yogyakarta: Kanisius.

Soekmono, R., 1990, Pengantar Sejarah Kebudayaan Indonesia, Yogyakarta: Kanisius Sugiyono. 2013, "metode peneliti kualitatif dan kuantatif dan R\&D. Bandung. Alfabeta.

Sutrisno, Mudji dan Putranto, Hendar. 2005. Teori-Teori Kebudayaan. Yogyakarata: Kanisius Yogyakarta.

Soekanto, Soerjono. 2013. Sosiologi Suatu Pengantar. Jakarta: Raja Grapindo Persada.

Usman, Hasan, Haji, 1988, Pranan Kebudayaan Daerah dalam Menunjang Pembangunan Nasional, Nusa Tenggara Timur: Panitia Pelaksana Temu Budaya Daerah Tingkat I.

Verheijen, jilis, A.J., 1991, Manggarai dan Wujud Tertinggi, Penerjemah: Alex Beding dan Marcel Beding, Jakarta: IIPI_RULL.

Yatman, Darmanto, 1988, Pandangfan Pemangku Kebudayaan Daerah Nasional Indonesia, Surakarta: Kantor Wilayah Departemen pendidikan dan Kebudayaan Propinsi Jawa Tengah. 